\title{
Article \\ A Swarm of Injustice: A Sociopolitical Framework for Global Justice in the Management of the Desert Locust
}

\author{
Jeffrey A. Lockwood ${ }^{1, *}$ and Michael Christopher Sardo ${ }^{2} \mathbb{D}$ \\ 1 Department of Philosophy and Religious Studies, University of Wyoming, 1000 E. University, \\ Laramie, WY 82071, USA \\ 2 Department of Politics, Occidental College, 1600 Campus Road, Los Angeles, CA 90041, USA; \\ msardo@oxy.edu \\ * Correspondence: lockwood@uwyo.edu
}

Citation: Lockwood, J.A.; Sardo, M.C. A Swarm of Injustice: A Sociopolitical Framework for Global Justice in the Management of the Desert Locust. Agronomy 2021, 11, 386. https://doi.org/10.3390/ agronomy11020386

Academic Editors: Michel Lecoq and Arianne Cease

Received: 22 January 2021

Accepted: 19 February 2021

Published: 21 February 2021

Publisher's Note: MDPI stays neutral with regard to jurisdictional claims in published maps and institutional affiliations.

Copyright: (c) 2021 by the authors. Licensee MDPI, Basel, Switzerland. This article is an open access article distributed under the terms and conditions of the Creative Commons Attribution (CC BY) license (https:/ / creativecommons.org/licenses/by/ $4.0 /)$.

\begin{abstract}
In recent years, scientists and managers have advocated for the integration of the social sciences (particularly political science and economics) and the humanities (particularly moral philosophy) with the natural sciences (particularly entomology and ecology) in developing a full understanding of locust-management programs. In this paper, we pursue such a synthesis by using the desert locust (Schistocerca gregaria) as an exemplar case. After an overview of this insect's biology, ecology, and management, we provide a brief summary of the standard, moral theories (utilitarianism, deontology, and virtue ethics) and consider their shortcomings with regard to developing a framework for understanding the socioeconomic complexity of locust management. Next, we address some of the models of global justice and focus on two fundamental questions: Who is a moral agent with regard to desert locust management, and how should we justly distribute the responsibilities among agents during preventive and reactive modes? After identifying the agents, we use a fourfold set of principles to construct a framework for locust management consistent with global justice and apply this conceptual system to two hypothetical scenarios. We conclude with some observations from political philosophy that offer progress toward a comprehensive and applicable theory for locust management in the context of global justice.
\end{abstract}

Keywords: locust plagues; preventative and reactive programs; moral agents; capacity-and-capability model; social connections model; responsibility; global justice

\section{Introduction}

Locusts (Orthoptera: Acrididae) are among the most devastating pests in human agriculture. This common name for these insects is derived from the Latin locus ustus, meaning "burnt place," to describe the condition of the land after a swarm has passed. These insects have caused serious damage to crops and forage across the globe, and their depredations have become the basis for legends, myths, and-in recent times-staggeringly complex, multinational control programs. Aside from pandemics, no biological phenomenon afflicts a larger expanse of the Earth than locust plagues. For example, the desert locust, Schistocerca gregaria, spans 60 countries, generating cooperation (and conflict) across three continentsand arguably on all six inhabited continents if we include the role of international donors during insect-driven, humanitarian crises.

Human efforts to manage locust outbreaks entail the integration of virtually all fields of academic inquiry. Understanding the insects themselves requires the study of biology (evolution, genetics, biochemistry, physiology, and anatomy), while their ecology demands an understanding of atmospheric science, chemistry, soil science, hydrology, and botany, among other fields. The movement of locusts across borders necessitates the inclusion of political science and economics, along with cultural and anthropological research. Grasping the complex international aspects of locust management also requires the study of history, including the legacy of colonialism. And the conflicts and harms arising from 
locust infestations raise important questions with regard to environmental ethics and global justice.

Such complexity calls for an overarching framework for understanding the locusthuman nexus, which integrates interdisciplinary scholarly research and real-world practices. While universities, government agencies, and international organizations "talk the talk" of interdisciplinary collaboration, locusts provide an urgent test of our willingness and ability to "walk the walk". In particular, we argue that the scale and magnitude of locust swarms raise crucial normative questions of global justice that cannot be answered by natural scientific inquiry alone. Such questions include the scope of moral and political obligations, whether transnational inequalities constitute a question of justice, and the proper agents responsible for implementing the standards of global justice. However, while the global justice literature often engages environmental questions, such as natural resource inequalities and climate change, locust plagues have garnered little attention in that field. In this paper, we hope to make a modest contribution-along with those who have already taken the first, small steps-toward a desperately needed collaboration of the natural sciences, social sciences, and humanities to address an ongoing and worsening cause of human suffering.

In this paper, we review the ecological and economic relationships between humans and locusts, with particular attention to why the challenges with respect to pest management cannot be mitigated solely in terms of the natural sciences, and how these shortcomings are a matter of justice. We briefly review the triad of standard ethical theories (utilitarianism, deontology, and virtues) and make the case that features of locust population dynamics require us to apply theories of global justice. From this argument, we then address the two fundamental questions of who an agent of justice is and how responsibility should be fairly distributed among these agents. We conclude with the application of the most compelling theoretical frameworks to simplified but realistic case studies to illustrate how the principles of global justice could inform our policies and actions.

\section{Background: Entomology, Society, and Politics}

\subsection{Locusts and Humans}

\subsubsection{Locust Biology}

Locusts are those species of grasshoppers that exhibit behavioral, anatomical, and physiological "phase changes" associated with aggregation and migration under crowded conditions. At high population densities, these insects undergo a transformation from the solitarious to the gregarious phase, during which they shift from avoiding one another to seeking close proximity with conspecifics. In the gregarious condition, the immature hoppers (nymphs) aggregate in dense bands that march across the habitat, and the adults form swarms that fly long distances [? ? ? ]. Tactile and olfactory cues are used by the insects to assess population densities and thereby initiate the reversible phase transformations [? ].

While some locust species are chronic hazards to agriculture and require treatment in most years, many of the most serious pests exhibit erratic population dynamics with periods of low densities punctuated by irruptive population growth requiring emergency interventions to avoid disastrous crop losses [? ? ? ]. In this paper, we will focus attention on the prototypical, widespread, and damaging species, the desert locust, which extends across 29 million $\mathrm{km}^{2}$ from India to Mauritania [? ].

Like many other locust species, S. gregaria's population dynamics are driven by weather. In particular, precipitation is primarily responsible for indirectly triggering the gregarious phase by generating abundant vegetation in the desert habitats where the solitarious locusts chronically persist. In conventional terminology, a period of low population density in nonagricultural habitats is called a recession. An outbreak is characterized by localized, small swarms with most populations remaining solitarious. During an upsurge, continuing regional rains allow locusts to increase in density across multiple generations with more frequent swarming. Perhaps $20 \%$ of upsurges develop into plagues with swarms infesting an entire region causing extreme damage to crops and pastures [? ]. 


\subsubsection{Locust Management}

The management of the desert locust involves two, distinct strategies: the chronic, localized management of incipient outbreaks to prevent large-scale population increases; and the acute, reactive, large-scale treatment of hopper bands and adult swarms when prevention fails. The challenge in shifting from reactive to preventive modes strategy is the so-called "vicious cycle" [? ? ? ] in which funding is abundant during plagues due to an urgent need to mitigate suffering, while between these humanitarian crises, there is diminished support for surveillance and tactical treatments.

During plagues of the desert locust, millions of people relying on subsistence farming may require food aid [? ]. The socioeconomic damage is further manifest as pastoralists sell their livestock at deflated prices to meet acute needs. As such, the harm to agriculturalists can extend for years as they incur debt or lose their land entirely. In addition, there is a negative impact to child education and health that persists well beyond the locust plague [? ? ]. Reactive-control programs rely heavily on broad-spectrum chemical insecticides applied by aircraft and ground sprayers. Positioning equipment and supplies in pursuit of fast-moving swarms is a significant logistical challenge. Biological insecticides have made some inroads, but because these pathogenic products are largely restricted to locusts, the market is erratic and requires dramatic, rapid increases in production during an upsurge or plague. Moreover, once a plague has subsided, these materials cannot be used for other pests, and storage stability is limited. While some broad-spectrum chemical insecticides can find agricultural uses after a reactive program, large stocks of obsolete, environmentally undesirable or banned insecticides have accumulated in locust-afflicted countries [? ].

A strategy of preventing locust plagues through locating and treating hopper bands and adult swarms during the outbreak phase [? ? ] is considered to be the most economically efficient use of resources [? ? ? ] (for a dissenting view, see [? ]). Satellite imagery combined with geographic information systems is used to find green vegetation that signals the possibility of breeding conditions in desert areas, as locusts encounter abundant food and moist soil for their eggs [? ]. But ultimately, scouts must go into the field to assess infestations and apply localized treatments-this a weak link in that the locusts often arise in places that are extremely remote and locations with military hostilities or minefields from previous conflicts [?]. The actual efficacy of preventive programs in most countries within outbreak areas can be called into question by consideration of the frequent upsurges and plagues that have developed in the last 35 years.

\subsection{The Desert Locust in a Sociopolitical Context}

\subsubsection{Need for New Approaches}

The ecological and social challenges arising from preventive and reactive locustmanagement programs are too interdependent to be addressed through the natural sciences alone [? ]. Although biologists have pursued studies of transboundary coordination, risk management, stakeholder strategies, and economic cost-benefit analyses, social scientists have rarely been involved, with a few laudable exceptions (e.g., [? ? ? ? ]). As argued by Zhang et al., "The sustainability of locust and grasshopper control must be better assured by considering not only scientific and technical aspects, but also socioeconomic mechanisms involved in the management of these pests" [? ] p. 27. However, there is a further consideration. A sound system of locust management must be not only efficacious but moral, as unjust demands on countries and regions are sociopolitically unsustainable.

The Food and Agriculture Organization (FAO)'s proposal for an improved financing system illustrates the problem of analyzing desert locust management without regard to ethical considerations [? ]. The prospectus includes a plan for funding during various periods of locust population dynamics, but there is no consideration of who ought to be responsible for providing support or how this responsibility should be fairly allocated. In this example, as in many others, there is a valuable, descriptive critique (i.e., what is being done) but little or no normative analysis (i.e., what should be done). 
In a similar sense, intense conflicts over the goals of desert locust management are exemplified by the 2020 exchange between Tom, US Ambassador and Permanent Representative, United Nations Rome Based Agencies, and Metlerkamp, research fellow at the Environmental Learning and Research Center Rhodes University. Although competing socioeconomic ideologies were presented, neither side in this debate went beyond simple, normative assertions (i.e., that industrial or agroecological values were to be preferred) [? ? ]. As such, the competing and compelling ethical foundations were largely obscured by political rhetoric.

The current locust plague reflects ecological and political conditions [? ], including armed conflicts among weak states in the Middle East and eastern Africa, which precluded effective preventive programs following heavy rains [?]. The early outbreaks went undetected, allowing swarms to develop [? ]. Using a spatially explicit multiagent model, Gay et al. [? ] found that a preventive program can be nullified with just $5 \%$ of the territory having limited access. The study concluded that plagues are most likely to originate in weak states with larger areas inaccessible to pest managers. Add to this the reluctance of donor nations to provide funds to countries that engaged in terrorism and human-rights abuses (e.g., Sudan), and the potential for locust outbreaks to emerge undetected and unimpeded is significant [? ]. And this is not a new problem, as the 1986-1989 plague was substantially attributable to a lack of early intervention due to armed conflict in the primary locust breeding areas of Eritrea and Sudan [? ].

Natural disasters have been analyzed using various risk governance, operational, and funding models (e.g., [? ? ? ]), but such theories rarely consider locust plagues. Although locust control is increasingly viewed as being the management of a natural hazard [? ], the desert locust presents several unique features that must be considered in developing any viable, socioecological analysis. These qualities include ecological dynamics, geographic scale, geopolitical complexity, and socioeconomic factors.

\subsubsection{Distinctive Features of Locust Plagues}

With respect to ecological dynamics, since 1860 there have been 10 upsurges lasting $1-4$ years (mean $=2$ years) and nine plagues lasting for $1-22$ years (mean = 10 years) [? ] This means that recession periods are the norm and can last more than a decade. During recessions, international funds, along with regional, national, and local resources are shifted to urgent problems rather than outbreak-prevention programs for locusts. However, it is important to recognize that past ecological patterns may not be reliable indicators of future dynamics, as climate change is likely to exacerbate the unpredictability and intensity of plagues [? ? ]. With rising temperatures, insect development is accelerated (locusts typically take about a month from hatching to fledging) [? ] and flight performance (speed and distance) may be enhanced [? ]. Extreme weather events make forecasting locust dynamics increasingly difficult. For example, despite a general trend of increased droughts in Africa [? ], the current plague developed during unusually heavy rains from two tropical cyclones in the Arabian Peninsula in just 5 months [? ? - phenomena linked to the rapid warming of the Indian Ocean [?].

In terms of geographic scale, the desert locust afflicts $10 \%$ of the human population [? ]; only pandemics have a wider scope. The current plague involves nine countries (Ethiopia, India, Iran, Kenya, Pakistan, Somalia, South Sudan, Uganda, and Yemen) with swarms moving into parts of six other nations [? ]. Food shortages may soon resemble those in 2003-2005, when crop loss exceeded 80\% in Burkina Faso, Mali, and Mauritania despite the treatment of 13 million ha at a cost of USD 500 million [? ? ]. Upsurges and plagues produce mismatched scales in which the potential for harm is widespread and control operations must be dispersed across enormous areas to track swarms moving up to $150 \mathrm{~km} /$ day, but damage is highly concentrated wherever locusts descend to feed. With both reactive and preventive management, the costs accrued in one place yield benefits elsewhere. Individualizing costs and collectivizing benefits becomes a serious challenge in terms of funding and cooperation. 
The spatial scope of the desert locust leads to geopolitical complexity. A brief overview provides a sense of the international efforts [? ]. The Food and Agriculture Organization (FAO) of the United Nations has established three Regional Commissions for Locust Control (western, central, and eastern, totaling 56 countries) that obligate member states to develop monitoring and control programs through national centers or ministries of agriculture. The FAO also hosts: (1) the Desert Locust Control Committee, which is composed of national representatives and coordinates monitoring and control plans; (2) the Desert Locust Information Service, which provides data, analyses, and forecasts; and (3) the Emergency Centre for Transboundary Plant Pests, which mobilizes emergency aid provided by donors such as USAID (USA), DGIS (the Netherlands), CIRAD (France), CIDA (Canada), SIDA (Sweden), ODA (UK), and GTZ (Germany) [? ]. Different countries and cultures give rise to various challenges, such as the implementation of control programs during Ramadan, the acceptability of locusts as human food, the reluctance to accept foreign aid, and the movement of swarms across borders, which erodes fragile relations between hostile countries [? ].

Socioeconomic factors exacerbate the spatiotemporal challenges. Standard economic analyses of desert locust-management programs have been criticized for omitting the perspectives of nomads, the value of food security, the costs of environmental damage, the sociological constraints in different countries, and the humanitarian benefits of pest management [? ]. In large part, these insects are found in impoverished nations where colonial legacies have created weak national governments with continuing dependence on donors for the costs of preventing or controlling locust plagues [? ]. In turn, perverse economic incentives may delay a poor nation's response to outbreaks in order to generate more foreign aid, given the opportunities for lucrative contract services during a plague. If the afflicted people are subsistence agriculturalists, then other nations, and even the urban centers within an infested country, are not directly harmed and assistance becomes less urgent, particularly if locust control competes with more dire threats (e.g., the current plague is unfolding at the same time as the COVID-19 pandemic).

In sum, it is evident that the ecological, geographical, geopolitical, and socioeconomic factors that shape the course of desert locust population dynamics and human responses, contribute in clear but complex ways to the unjust distribution of both the costs of preventive and reactive programs and the harms resulting from the failure of these interventions.

\section{Locust Swarms as a Question of Global Justice}

\subsection{Locusts and Justice}

\subsubsection{The Limits of Individualistic Ethical Theories}

Traditional theories of ethical and moral obligation identify principles that determine the proper moral action for individuals to take. Utilitarian principles emphasize the consequences of action, arguing that the moral action is that which produces the greatest good for the greatest number [? ], while deontological principles defend absolute duties that must be followed regardless of their consequences [? ]. The third traditional school of thought, virtue ethics, takes the position that we should cultivate character traits through practice so that individuals will develop their fullest, human potential [? ].

These ethical positions can fruitfully expand the scope of one's moral obligations. For example, Singer has argued, because pleasure and pain are universal, the obligation to reduce suffering transcends national boundaries [? ]. There is no difference, in his framework, between letting a child drown in front of you for fear of damaging your expensive clothing and purchasing expensive clothing in the first place, when that money could be used to alleviate starvation and disease in other countries. Therefore, he concludes, "If it is in our power to prevent something bad from happening, without thereby sacrificing anything of comparable moral importance, we ought, morally, to do it" [? ] p. 231. A similar argument could be reached through deontological reasoning, contending that we have an absolute duty to preserve human dignity regardless of consequences. However, as 
O'Neill (1993) [? ] contends, such duties are "imperfect," meaning that while we have an absolute duty not to directly impair the dignity of another person ourselves, promoting the dignity of distant others would be beneficent, but not morally obligatory. While virtue ethics presents a more difficult case, as such theories emphasize the particularity of ethical communities and traditions [? ], Van Hooft argues that cosmopolitanism can be considered a virtue in a globalized world, in which individuals view themselves as citizens of the world and see their moral obligations extending globally [? ]. Therefore, whether taken as a moral obligation to prevent suffering, an imperfect duty to promote human dignity, or as an fulfilling the virtue of cosmopolitanism, the traditional ethical "triad" can provide good moral reasons why individuals should seek to provide aid - whether preventative or reactive- to those suffering from locust swarms.

While a detailed analysis of ongoing debates between these rival theories is well beyond the scope of this article, we note that there are significant challenges in applying these principles to desert locust management. For example, utilitarian calculations could in fact argue that locust plagues (we will use this term henceforth to include upsurges) are not worthy of moral consideration because resources could be more fruitfully put toward assisting refugees, battling climate change, or providing vaccinations against infectious disease. A similar line of argument was implicit in Tom's impassioned argument for using chemical insecticides to suppress the current desert locust plague, along with shifting global agriculture to an industrial model so as to produce abundant food at a low cost to feed as many people as possible [? ]. Similar challenges face deontological approaches, since humanitarian assistance would qualify as an imperfect duty: we ought to practice charity but we do not have a duty to donate to every person or nation requesting our assistance. Thus, for a locust-control program, deontology offers no way of determining how the general duty to assist others in need should be instantiated, nor is it the case that anyone is unethical for not providing aid to locust afflicted people if one discharges one's charitable duty in other ways. The result is an impotent demand that "somebody should do something," which is a common response during humanitarian crises. Virtue theorists fare little better, given widely divergent conceptions of the meaning of the virtues across different cultures. What constitutes the "good life" - or the full realization of human potential-for one culture or community may not for another, raising concerns of paternalism or cultural imperialism.

Additionally, moving from individual moral obligation to questions of collective action and responsibility creates further challenges. We cannot simply scale up these systems to make sense of the ethical obligations of collectives (groups play a vital role concerning the responsible and effective management of the desert locust) for two important reasons. First, there are collective duties or responsibilities that a society is obligated to meet, but that no individual is blameworthy for failing to fulfill (e.g., a society ought to provide education and healthcare to people, but no particular person is ethically required to become a teacher or doctor). Second, because collectives are internally diverse with respect to power, influence, privilege, and causal relation to any particular harm, the question of allocating responsibility becomes vital. To take Singer's example of a child drowning in a river: If a dozen people see the child struggling, the problem of who should act gives rise to questions such as, "Who is trained in lifesaving?" "Does anyone have a special relationship with the child?" "Did someone cause the dire situation?" and "Can we form a human chain to reach the child and thereby reduce individual risk?" Given the cost of acting (jumping into the river to save a drowning child or donating funds to save hungry farmers), there is an incentive to wait for others who are more willing and able to intervene [? ].

As such, cases of shared responsibility require a framework for justice. This is not to say that justice is devoid of utilitarian or deontological elements, but that the standard theories are not the principled foundations for collective, moral, and political action. Our more fundamental concern, however, is that relying upon these moral theories in isolation overlooks the nature of locust plagues as an injustice. Given the complex cultural dynamics within which the prevention, management, and harms of locust plagues are embedded, 
individuals trying to fulfill their moral obligations-whether to alleviate suffering, promote human dignity, or practice the virtues-find that their actions are mediated by social, political, and economic forces beyond their control. This can be a disempowering realization, leading otherwise well-intentioned individuals to lament that there is nothing they can do to solve the problem. More fundamentally, these ethical approaches tend to treat human suffering in a vacuum, as an exogenous fact or tragedy that must be morally remedied like a tornado devastating a farm community. Our contention, however, is that locust plagues are better understood as injustice arising through the interaction of natural and human processes.

\subsubsection{Injustice: Beyond Bad Luck}

Not every inequality connotes an injustice. Some people are taller or younger than others and some countries have better soil or more minerals than others, and these unequal qualities are not unfair. Likewise, in the context of natural phenomena, inequalities may arise because someone is struck by lightning or a region is more prone to earthquakes. Given the sentiment expressed by Hayek that justice "ought to be confined to the deliberate treatment of men by other men" [? ] p. 163, it is tempting to treat locust plagues, and other natural disasters, as misfortunes, tragedies, or bad luck, rather than injustices. Such thinking misunderstands the nature of justice and the particular injustice of natural disasters in fundamental ways.

Justice is often understood in distributive terms. Such a conception has a long pedigree, dating to Aristotle's argument that justice entails treating equals equally and unequals unequally, when such inequalities are morally relevant (e.g., sentience or nonsentience rather than male or female). Sandel helpfully summarizes this conception as how a society "distributes the things we prize-income and wealth, duties and rights, powers and opportunities, offices and honors," or ensuring that society "gives each person his or her due" [? ] p. 19. To understand locust plagues as injustices, under this framework, is to highlight the inequitable distribution of harm they generate.

Rawls' conception of "justice as fairness" is perhaps the most well-known and influential account [? ]. This theory begins with a thought experiment: Imagine that you are behind a "veil of ignorance" such that you do not know your particular characteristics (nationality, ethnicity, wealth, gender, etc.) and you must develop the principles that will apply when you reenter the world. Rawls maintained that in this "original position," rational individuals will select three impartial rules of governance: the Liberty Principle granting all individuals a right to basic freedoms, the Equality Principle granting each person a right to the same opportunity of acquiring resources as others with the same natural abilities, and the Difference Principle allowing inequalities as long as they benefit the worst-off individuals. Rawls' goal is to nullify "the accidents of natural endowment and the contingencies of social circumstances" that are "arbitrary from a moral point of view" [? ] p. 15. Such thinking can be applied to the question of locust plagues, by considering the contingencies of birth (e.g., geography) that make one more susceptible to suffering harm. Resources should be distributed to benefit those worst off in society, to nullify the negative effects of these contingencies.

Justice should not only be understood in terms of material distributions, however. Following Young (1990 [? ] p. 37), injustices are more fundamentally understood as social and institutional conditions that create "oppression, the institutional constraint on selfdevelopment, and domination, the institutional constraint on self-determination" [? ] p. 37. Goodhart similarly describes injustices as "deformit[ies] in social relations [that] create, sustain, or contribute to subordination" [? ] p. 143. In this conception, the true injustice of locust plagues lie in the social, political, and economic institutions and structures that create unequal patterns of vulnerability, adaptive capacity, and suffering in the first place. In either Rawls' or Young's conception, locust plagues should not be written off as mere tragedies of nature to be remedied, but as injustices generating moral and political responsibilities for two crucial reasons. 
First, human influences may make natural events more frequent, severe, or prolonged. Hurricanes, floods, droughts, and wildfires occur without human intervention, but anthropogenic climate change is worsening these disasters. In terms of acridid population dynamics, rangeland grasshopper outbreaks are natural phenomena in the western US, but the use of broad-spectrum insecticides that eliminate parasites and predators increases the duration and intensity of these infestations [? ]. With regard to desert locusts, upsurges have been attributed to both the failure of countries to implement preventive management methods [? ? ] and the triggering of population increases as a consequence of climate change [? ? ].

Second, we must consider the allocation of the economic and social costs of natural disasters, which may be unjustly distributed even with random events. For example, the damage of an earthquake or hurricane may be far greater for people lacking the resources to access healthcare or rebuild houses. However, even if humans are partially or wholly responsible for a natural disaster, there is no injustice if those who allowed the problem to develop (e.g., by neglecting to take steps to prevent harm) or benefited from fostering the adverse environmental conditions (e.g., by accumulating comforts and conveniences that emit greenhouse gases), accrue the costs. However, with phenomena such as climate change and locust plagues, the costs are primarily borne by those lacking wealth and power-impoverished countries, former colonies, unstable governments, and subsistence agriculturalists who did not neglect to act or benefit from inaction [? ? ? ].

Therefore, locust plagues should be understood as what Shue calls a compound injustice, which occurs "when an initial injustice paves the way for a second, as when colonial exploitation weakens the colonized nation to such an extent that the colonizer can impose unequal treaties upon it even after it gains independence" [? ] p. 4. In the case of locust plagues, existing inequalities in the global political-economic order-themselves legacies of colonialism [? ]-leave the already-vulnerable both more susceptible and less equipped to effectively respond, manage, and adapt to locust plagues.

To treat locust plagues as mere bad luck, would, following Shklar, impose a "sense of tragic inevitability upon events that are in fact entirely (or at least substantially) amenable to purposive human alteration" [? ] p. 70. This fatalism then obscures questions of responsibility and ultimately reifies existing inequalities as natural. Similarly, Erskine contends that retrospective ascriptions of blame after international, natural disasters can distract from addressing how responsibilities should be distributed in the future [? ]. Who has a moral duty and what constitutes a just allocation of such responsibilities are as vital as questions about logistics, financing, and politics. Dealing with prospective responsibilities to avert future crises is more important than investing energy into assigning retrospective culpability when nothing (or too little) was done. Vague references to the failure of the "international community" are singularly unhelpful. It is the purpose of this paper to open a conversation as to how we might prospectively identify the moral agents and just distributions of responsibilities in the context of a sound sociopolitical and ecological understanding of desert locust management.

\subsubsection{The Challenge of Global Justice}

The normative concerns with desert locust management become even more challenging when placed in their global context. As Zhang et al. argue, "Robust mechanisms need to be put in place to ensure continuous financial support at national and international levels so that treatment programs can be put in place in a timely manner as part of successful strategies of sustainable preventive management" [? ] p. 26. If one's concern is justice, desert locust management inevitably raises questions of how to give "each person his or her due." Who should provide this financial support: domestic governments, foreign governments, international organizations, or nongovernmental organizations? To whom should such financial support flow? How should different projects be prioritized? What do citizens of one nation-state owe to citizens of distant ones? If justice concerns not only distributive questions, but also, as Young and Goodhart contend, questions of social 
structure, institutional domination, and oppression, these questions are even more vexing [? ? ]. We must ask what obligations do nation-states (or their citizens) have to reform unjust institutions in other nation-states, or would such actions be themselves unjust? If the institutional structure in question is the global political-economic order, including the structure of global trade, international patent law, and humanitarian assistance, what obligations can individuals realistically and meaningfully have with respect to such a structure? The debate over such questions in the literature on global justice is voluminous, and our treatment will necessarily be schematic. However, our contention is both that this body of literature can be fruitfully used to study the ethical challenges of desert locust management, and that the question of desert locust management can add further richness to the relatively abstract discussion of global justice.

Much of the debate concerns whether justice is even a meaningful concept at the global level, or if the scope and boundaries of justice should be restricted to more formal political communities. We begin with a consideration of cosmopolitan views and then address statist views.

Cosmopolitans, as we have earlier noted, argue that both membership in a political community and physical proximity are both morally arbitrary when evaluating one's moral obligations. Emblematic of this line of argument is Singer's insistence that there is no morally relevant difference between letting a child drown within eyesight and letting a child starve to death on the other side of the world [? ]. One has a moral obligation to alleviate suffering, wherever it occurs.

In an increasingly globalized and interconnected world, it becomes difficult to sustain the idea that moral obligations stop at national boundaries, even if one rejects Singer's utilitarian reasoning. While Rawls believed that his principles of justice could not be applied beyond the boundaries of autonomous nation-states [? ? ], Beitz argues that this formulation fails to recognize that the interdependency of modern societies undermines national autonomy and creates a new basis for justice [? ]. Because a state's endowment of natural resources are contingent-and thus morally arbitrary in a Rawlsian sense-Beitz contends that "principles of distributive justice must apply in the first instance to the world as a whole, then derivatively to nation-states" [? ] p. 383.

Other approaches focus less on Rawlsian contractualism, but on the conditions for living a dignified life. Shue argues that all human beings are entitled to the protection of certain basic rights, which constitute "everyone's minimum reasonable demands upon the rest of humanity" [? ] p. 19, while Nussbaum instead focuses on human capabilities that are necessary for flourishing (e.g., bodily health and integrity, self-determination, and free expression), to which all human beings are entitled regardless of geographic location [? ]. Insofar as locust plagues cause human suffering, deprive individuals their basic rights of subsistence and security, or undermine their ability to flourish, they generate moral obligations to provide aid regardless of political boundaries.

Statists object to such arguments despite their appeal to moral intuitions about universality and equality. Nagel argues that justice refers specifically to duties shared by co-citizens, by virtue of living under a common sovereign [? ]. His argument is not merely pragmatic - that without a world government is difficult if not impossible to enforce the demands of cosmopolitan justice-but that living under a common sovereign who wields violence in one's own name creates special ethical bonds among compatriots that give rise to the demands of justice. While we have basic humanitarian obligations to all people to alleviate extreme distress, the demands of justice, which concern questions of equality and political relationships, are properly bounded by political membership. Miller critiques cosmopolitan theories of justice for imposing uniform sets of rights and duties over and against the diversity of communities around the world [? ]. Cosmopolitanism excludes "the possibility that there exist deep cultural differences between and among societies which the members of each find valuable, and which they want to see protected by political means" [? ] p. 84. While these statists may accept that providing humanitarian assistance in response to locust plagues may be morally good, they would reject that the demands 
of justice generate equal responsibilities to victims of distant locust plagues as they do to those suffering from hunger or poverty within their own political communities.

Eschewing the binary choice between cosmopolitans and statists, we follow theoretical projects that navigate between the extremes of the overwhelming burden of cosmopolitan justice on one hand and the moral isolationism of statist conceptions of justice on the other. Rejecting the logic that the demands that justice must either be restricted to one's own political community or have universal reach, Forst argues that many questions of transnational justice involve multiple overlapping relationships of power, domination, and inequality at local, national, and transnational scales [? ]. Shifting perspective from abstract ideals of justice towards actual victims of injustice, "... reveals that theirs is a situation of multiple domination: most often they are dominated by their own (hardly legitimate) governments, elites, or warlords, which in turn are both working together and are (at least partly) dominated by global actors... The various contexts of justice-local, national, international, and global - are connected through the kind of injustice they produce, and a theory of justice must not remain blind to this interconnectedness" [? ] (pp. 166-167).

Locust plagues can best be understood as involving multiple contexts of justice-from domestic concerns of failed preventative management and socioeconomic inequalities that leave the vulnerable at greatest risk, to transnational economic and political forces that weaken state capacity to address these compound challenges, to the broader contexts of global climate change and the lasting legacies of colonialism on economic development. Given this complexity, the proper question of justice is not, "Do I have any moral responsibility to assist those suffering from locust plagues?" Instead, in an attempt to lay the foundation for what we hope will be a continuing discourse on moral agency and the just allocation of responsibilities pertaining to locusts, we consider two essential questions: Who are the moral agents that can be held accountable for achieving justice, and how should the responsibilities for reactive and preventive programs be fairly distributed among these agents?

\section{Moral Agents in Locust Management}

\subsection{Who Is Responsible?}

Individuals are paradigmatic moral agents, having the capacity to understand and respond to ethical obligations. The ability to be morally responsible is often taken as a hallmark of moral personhood, distinguishing human persons from other animals. As Kant writes, "A person is a subject whose action can be imputed to him" [? ] p. 16. However, other types of agents are also treated as capable of bearing moral responsibility, including collectives [? ], states [? ], and international institutions [? ]. As O'Neill argues, theories of justice that do not identify which agents are responsible for realizing them are necessarily incomplete and generate considerable theoretical and practical challenges [? ]. For example, the Universal Declaration of Humans Rights adopted by the United Nations in 1948 asserts that individuals have certain rights, but fails to specify who has the corresponding duties. The Declaration contends that every individual and "organ of society" should strive to advance human rights, but tacitly identifies states as the primary agents without any explicit rationale.

When considering who should be responsible for reactive and preventive programs for the desert locust, are the proper subjects of moral accountability subsistence farmers, global citizens, rural communities, scientific organizations, local governments, regional governments, ministries of agriculture, afflicted nations, foreign governments, relief organizations, corporations, and international bodies [? ? ? ? ? The result is a cosmopolitan conception of individualized rights enmeshed within a vaguely statist view of moral duties. While an Ethiopian farmer has a right to avoid starvation due to desert locust damage, who is morally obligated to treat the devastating plague is not evident.

One might intuitively contend that whoever is causally responsible for a harm is a moral agent. Indeed, responsibility is often, as Young summarizes, assigned "to a particular agent (or agents) whose actions can be shown to be causally connected to the circumstances 
for which responsibility is sought" [? ] p. 116. However, causal responsibility is neither necessary nor sufficient for moral responsibility. One can cause harm to another person purely by accident and so accrue no moral responsibility, and one can be obligated to provide aid to a suffering individual without having caused the harm. The desert locust case demonstrates this point: No single agent is uniquely causally responsible for a locust plague, but that does not eliminate all responsibility to provide preventative and reactive aid. We contend that causal contribution is best understood as a factor in allocating responsibility rather than assigning agency. Therefore, we consider two broad approaches to identifying the moral agents responsible for global justice, with particular attention to the management of the desert locust: the capacity-and-capability model and the social connectionist model. Before addressing these, however, a crucial distinction must be made.

Not every assemblage of moral individuals constitutes a new moral agent [? ? ]. A mere grouping of people (or collection of social units, such as nations) can be termed "aggregate collectivity," insofar as the group has no different or greater obligations than the sum of its parts (e.g., the spectators at a sporting event or the countries comprising Asia). This contrasts with "conglomerate collectivity," in which the assemblage has an identity and continuity over time, organizational and decision-making procedures, and an ability to take purposive action through deliberative goals. Such institutional agents can possess novel or emergent moral responsibilities beyond those of their members, and might be exemplified by the United Nations or the Global Locust Initiative (2020) [? ]. It is sometimes useful to also distinguish primary from secondary agents of justice, the former exerting control over the latter (e.g., the UN versus the UNFAO, or the US Congress versus the US Agency for International Development) [? ].

\subsection{Contemporary Models}

\subsubsection{Capacity-and-Capability Model}

$\mathrm{O}^{\prime} \mathrm{Neil}$ contends that institutional or collective agents of justice must possess two features: the capacity to make moral decisions and the capability to affect these decisions [? ]. Along these lines, Erskine contends that institutional agents have capacity insofar as they can engage in moral deliberation and thereby take on collective responsibility [? ]. For example, the FAO's Desert Locust Control Committee, the government of Kenya, and Dow AgroSciences all have the potential to assess their organization's collective duty to respond to a locust plague. Each of these groups possesses the temporal continuity, analytical processes, and goal-setting mechanisms for conglomerate collectivity.

Capacity is a necessary but insufficient condition of being an agent of justice, as good intentions without commensurate actions might satisfy a deontological standard, but most views of justice require a consequentialist element as well. As such, agents must also possess the capability to actualize the outcome of their moral reasoning-to deploy resources in actual circumstances [? ]. In essence, this requirement reflects the ethical principle that "ought implies can" - that to say one should act in some manner entails that the agent has the ability to do so. However, as Caney argues in the context of climate change, there are considerable limitations to ascribing responsibility on the basis of capacity alone, as it ignores how injustices themselves produce inequalities in capacity and can absolve those who have contributed to an injustice if they now lack effective capacity [? ].

Additionally, capability is a continuous, rather than discrete, feature of an institutional agent. As Sardo argues, using discrete qualities of agents as criteria for responsibility overlooks the social, economic, and political structures within which agents are embedded and that generate differences in capacity [? ]. For example, an agent that has fostered dependency and thereby diminished the capability of another agent may thereby become responsible for either providing resources or developing autonomy and capability in the reliant agent (e.g., a European nation in relation to its former African colony). Therefore, Sardo argues that in the case of complex and compound structural injustices, such as climate change and, as we contend, locust plagues, responsibility should be ascribed on 
the basis of social-relational criteria, rather than individualistic ones [? ]. One such theory of relational responsibility is Young's "social connections model" [? ? ].

\subsubsection{Social Connection Model}

Although cosmopolitan principles of justice would apply to all moral agents, $\mathrm{O}^{\prime} \mathrm{Neil}$ raises the concern that ceding the obligation to act on behalf of afflicted people to global institutions could degenerate into a kind of centralized tyranny [? ]. One approach to avoiding such a situation would be to disperse the responsibility among a plurality of agents. Such a strategy can be found in Young's critique and reconceptualization of Rawls's understanding of the basic structure of society, in which she makes the case that modern life entails vital, mutual interests extending far beyond the borders of one's nation into a system of international connectivity [? ? ].

The social connections model is based on the recognition that people participate in political institutions as a response to individuals being socioeconomically interdependent, and that these connections often arise without regard to political boundaries. According to this view, truly global moral obligations, such as human rights, are not the proper realm of justice, as universals do not arise from, nor are they contingent upon, social relationships. However, all agents who contribute by their actions to economic and political systems that yield unjust distributions of resources among affected countries have a responsibility to remedy these moral failings. This responsibility is different than the standard notion of liability insofar as many current injustices are the product of sociohistorical events giving rise to so-called structural injustices that are immoral in a way that is distinct from the wrongful action of either individuals (who may participate in and benefit from the structures while not having created them or intended harm) or states (which may not willfully diminish the well-being of the repressed people). As such, it is not possible to trace specific actions by a US citizen or the French government, for example, to the suffering of a chronically impoverished Somali farmer during a locust infestation.

The social connections model, therefore, can fruitfully negotiate between the cosmopolitan and statist conceptions of justice and responsibility. It recognizes the realities of economic interdependence without holding individuals responsible for rectifying every injustice everywhere on Earth. In the case of desert locust plagues, it does not blame individuals for the suffering caused by these disasters. However, individuals can be held responsible in a forward-looking sense to act not merely to provide humanitarian aid, but to work to reform the national and transnational institutions that unequally distribute the harm of natural disasters such as locust plagues. This responsibility is not universal, but adheres to those who participate in and benefit from the same structures and institutions that lead to the compound injustice of locust plagues.

\subsection{Inventory of Moral Agents in Desert Locust Management}

Our goal is not to settle theoretical debates between different theories of responsibility, but to draw on both the capacity and capability $(C \& C)$ model and the social connections (SC) model to identify responsible agents in the context of pest management. This yields a realistically complex suite of parties given the nature and scope of desert locust infestations.

\subsubsection{Multinational Agents}

The unspecified "global community" is an aggregate collective lacking the necessary qualities for moral responsibility. In terms of the desert locust, the dominant, conglomerate collective is the UN and its secondary agent, the FAO. This collective, along with its downstream organizations (Regional Commissions, Desert Locust Control Committee, and Emergency Centre for Transboundary Plant Pests) all have substantial capacities and capabilities, as well as elements of social connectivity. 


\subsubsection{National Agents}

At the national level, it is important to consider both strong and weak states. The former unambiguously meet the criteria of the C\&C model [? ]. The executive and legislative branches of these governments constitute the primary agents, with various development agencies being secondary agents (e.g., the French Agricultural Research Centre for International Development).

The agency of weak states is a matter of degree according to the C\&C model. Socalled quasi-states, exemplified by several countries in the Middle East and sub-Saharan Africa, are exceptionally dependent on foreign creditors and lack institutions to constrain or outlast the individuals holding power [? ]. As such, they exhibit aggregate, more than conglomerate, collectivity. In comparison, weak states have greater autonomy, although still depending to a substantial degree on international aid, which can impede their sovereignty [? ]. Miller contends that the wellbeing of weak states is largely a function of external, economic, and historic conditions that would entail the obligation of strong states via the SC model [? ]. A country having habitats that give rise to desert locust outbreaks is an ecological accident, which might be analogized to a person having a genetic handicap that entails dependency and hence generates a moral duty for others to provide accommodations.

\subsubsection{Nonstate Agents}

There are at least three nonstate agents of justice. First, NGOs of various types have capacity but often limited capabilities, although they actively cultivate social connectivity. Examples of these agents include international aid organizations (e.g., CARE and Mercy Corps) and university-based organizations (e.g., the Global Locust Initiative and Association for Applied Acridology International). Next, corporations meet the criteria of both the $\mathrm{C} \& \mathrm{C}$ and SC models. Although desert locust irruptions are too erratic for the agrichemical industry to bother shaping locust-management policies and markets (producers of locust-specific biological insecticides have a greater interest), their products are important to preventive and reactive programs. Just as it is sociologically simplistic to advance the Rawlsian or "realist" view that states act only in their own self-interest, corporations need not be solely committed to maximizing profits as exemplified by B-corporations and others with social responsibility provisions [? ]. And finally, the SC model suggests that citizens of industrialized nations bear some moral responsibility by virtue of their benefiting from structural injustices that disadvantage locust-afflicted people, although it must be recognized that their capability of meaningful action is extremely limited.

\section{Distribution of Responsibilities}

\subsection{Four Standards of Global Justice}

The C\&C and SC models allow us to generate an inventory of potentially responsible agents. However, given both the number of agents, at various scales, who have either the capacity to respond or are implicated by social connections, as well as the complexity of the challenge of desert locust management, such an inventory is necessary but insufficient. We also require a framework for distinguishing among these agents and allocating particular duties to particular agents. Neither the C\&C nor the SC model accomplishes this in isolation. As the proponent of the latter model, Young identifies "parameters of reasoning" that can be used to allocate specific duties, including capacity, privilege, interest, and ability [? ] (pp. 144-147). However, to better operationalize the standards for fairly distributing the responsibilities for preventative and reactive locust management, we turn to Miller's more perspicuous analysis, which applies to agents ranging from individuals to conglomerate collectives (international organizations, nations, corporations, etc.) [? ]. This model provides four concrete standards for allocating responsibility: causal, moral, capacity, and community. 


\subsubsection{Causal Responsibility}

That moral agents who cause harm to others bear a commensurate responsibility to correct the wrong is a commonsense moral intuition. However, as we have argued previously, causal responsibility is neither necessary nor sufficient to generate corresponding moral and political responsibilities, especially in cases of compound and structural injustices. Miller's principle of causal attribution can still be useful in distributing responsibilities to the responsible agents identified by the C\&C or SC models of responsibility [? ], especially when modified as Shue's (1999 [? ] p. 534) "greater contribution principle," which does not imply that the responsible agent is the exclusive cause [? ] p. 534. Of the agents who have the capacity to respond to locust plagues or participate and benefit from the global political-economic structures that leave some states more vulnerable to and unable to effectively manage locust plagues, greater burdens should be placed on those who have contributed more to the problem.

Applying causal responsibility to the case of locusts can be challenging, given that swarms (the proximate cause of human suffering) are not moral agents, while the contribution of moral agents-whether individuals, states, or international institutions-are indirect and mediated. However, as Sardo analogously argues, the proper object of responsibility for the structural injustice of climate change is not discrete greenhouse-gas emissions, but the global political-economic structures that both intensify fossil-fuel extraction and unevenly distribute the benefits of such vulnerability and the risks of climate-related hazards [? ]. In the case of locust plagues, climate change is aggravating the unpredictability and severity of plagues [? ? ]. As such, the industrialized nations with disproportionate $\mathrm{CO}_{2}$ emissions bear a commensurate, if partial, responsibility for the consequences of erratic and severe weather with regard to pest population dynamics. Additionally, colonial powers played a major role in creating weak governments, unstable societies, aggressive militaries, and dependent economies in their former colonies-all of which undermine both implementing preventive strategies and mounting reactive programs during upsurges and plagues. In an important sense, this complex network of causal responsibility involving locust plagues, climate change, and economic inequality might be best understood as constituting a global, structural injustice. Therefore, the idea of contribution should be expanded to include these climatic, geopolitical, and historical forces that unevenly distribute vulnerability and adaptive capacity for locust plagues.

\subsubsection{Moral Responsibility}

If an agent's harm is foreseeable, intentional, and unjustified (again, inequities can arise through legitimate processes), there is moral culpability - even without causal responsibility. For example, failure to monitor a risky situation could constitute wrongful neglect [? ]. In an international context, even excusable ignorance of how injustices arose does not obviate moral responsibility [? ]. In fact, Vanderheiden argues not only that ignorance is not exculpatory, but that agents have a positive responsibility to educate themselves to a reasonable degree about predictable natural disasters and other hazards [? ]. What matters is synchronic features (present considerations of an agent's obligations to those who are suffering, limited by the agent's ability to render aid and to bear sacrifice), rather than diachronic considerations (how the suffering came to be). Miller argues that while an agent may have a synchronic moral duty, having participated in the genesis of a harm also can entail moral responsibility [? ]. Hence, causal responsibility can engender moral responsibility, but it is not a necessary condition.

Therefore, greater burdens should be assigned to those agents in positions of relative power who foresaw, or should have foreseen, the hazards of locust plagues, but failed to take the necessary preventative action. This would place greater burdens on states and institutional agents than on individuals. Although countries with causal responsibility might have a greater duty to act, standing by while afflicted farmers or pastoralists suffer is not morally defensible even for those countries without a clear diachronic role in the crisis, when taking action could mitigate the harm suffered. Adapting the line of argument 
provided by Caney [? ], our options are to: ascribe mitigation responsibilities to the subsistence agriculturalists, do nothing and thereby allow serious harm, or ascribe duties to more powerful agents. The third option seems the only practical and principled course of action. However, we must keep in mind that "ought implies can" in formulating moral duties, so the pragmatic element of Caney's third option leads to the next standard with respect to global justice.

\subsubsection{Capacity to Act}

This principle states that those agents with the greatest power to remediate suffering are obligated to do so. In an international context, Miller contends that those with the most resources are expected to shoulder a greater proportion of the burden, a duty that amounts to a kind of progressive taxation [? ]. An objection to this standard is that the expectation would be a disincentive for wealthy nations to continue their financially successful practices if doing obligates them to ever greater contributions to poor nations. Miller replies that indefinite growth of production and consumption are not sustainable, regardless of whether global justice requires increased contributions [? ]. Moreover, there is no evidence that economic growth depends on unlimited incentives. Another concern is that the synchronic nature of capacity does not require that we consider how an injustice or crisis arose. However, capacity also does not preclude considering causal responsibility.

The application of the capacity principle to locust management is rather straightforward: Wealthier nations are morally obliged to provide greater financial assistance to support both preventative and reactive measures in response to locust plagues. However, it should be noted that money is not the only resource relevant to capacity. Some industrialized nations have greater, relevant scientific and technical expertise. Nor should we focus entirely on nations, as substantial capacity can also be found in universities (e.g., scientific and technical expertise) and corporations (e.g., insecticides, application equipment, and safety supplies). Although we cannot expect a company to donate materials, businesses have a moral obligation to sell their products without profiteering. It should be noted that the capacity to intervene during a plague might be different than that needed to develop and sustain preventive programs. Given the economic efficiency of prevention, an agent's capacity is greatly enhanced by contributing to preventive management. Some might object that capacity is an unrealistic standard in the absence of a sociopolitical relationship between donor and recipient. This brings us to the final principle of global justice.

\subsubsection{Communal Responsibility}

As our discussion of the scope of global justice suggests, social relationships are morally relevant with regard to the allocation of duties pertaining to global justice. Miller contends that a communitarian principle that recognizes special ties accords with our moral intuitions [? ]. For example, we accept, ceteris paribus, that duties to friends are greater than to strangers. If Young's social connections successfully makes the case that responsibility for harm derives from structural injustice, then it follows that an agent's responsibility to provide aid would likewise track structural or communal linkages [? ]. However, reducing connections, and hence obligations, to the level of individuals becomes morally impotent given a person's very limited ability to influence structural injustice within the international community (recall that "ought implies can"). The problem with an individualistic approach can be avoided by considering communal relations that exist among conglomerated agents. Nations, agencies, NGOs, and corporations may have particular relations with afflicted countries that entail ethical responsibilities.

With regard to locust management, countries sharing common languages, religions, and cultural practices may often be wealthy nations and their former colonies. Importantly, past relationships of unjust domination created international communities and hence particular moral duties - not by virtue of remediating historical wrongs (although this is relevant to causal responsibility), but by virtue of contemporary connections. So, European nations have particular obligations to their former African and Asian colonies that are 
afflicted by locusts. In addition, international communities such as the FAO's Regional Commissions for Locust Control generate mutual obligations. When member countries fail to pay their annual dues and the organizations are consequently unable to conduct preventive programs [? ], the resulting upsurges and plagues reflect an injustice and moral culpability within these regions. And finally, NGOs, religious denominations, universities, scientific organizations (e.g., the Orthopterists Society, which is an international group devoted to the study of grasshoppers, locusts, and their relatives), and other conglomerate collectives may have communal responsibilities through relationships to locust-afflicted countries, districts, or even villages.

\subsection{Resolving the Standards}

The principles guiding the just allocation of responsibilities among moral agents might be complementary in some cases (e.g., causal responsibility may align with moral responsibility, or causal responsibility may track communal responsibility). However, the principles may often be conflicting (e.g., an agent with the greatest capacity to act may have no causal responsibility) or unrelated (e.g., being agents within a community has no necessary relationship to those agents having the capacity to act). As such, how to integrate the four standards of global justice is a challenge for which there are at least four possible approaches [?].

\subsubsection{Particularism}

Few, if any, real-world cases will reduce to a single standard (e.g., a situation with capacity and no elements of causal, moral, or communal responsibility). On the other hand, there is no obvious formula for balancing the four principles, so we might abandon the search for a universal theory and simply deal with every case on its own terms. However, this ad hoc approach provides no guidance as to how the factors should be integrated in a consistent and rational matter.

\subsubsection{Master Principle}

We might attempt to defend one of the principles and set aside the others. However, arguing for a single consideration seems doomed, as there are sound reasons for each of the standards, and choosing any one of them could result in either solely backward-looking considerations, as with causal responsibility, or forward-looking considerations, as with moral responsibility. The choice of a master principle might also give rise to situations in which nobody would be obligated to help (e.g., an earthquake with the master principle of causal responsibility). There also are surely cases in which justice demands more than a single factor (e.g., a community of nations with radically unequal capacities).

\subsubsection{Integration}

The standards of global justice could be integrated in two ways. First, the principles could be applied in series (e.g., first moral responsibility, then causal, then communal, then capacity). However, the problem is that in any series, the initial standard will be a matter of degree, and in some cases a lower-order principle might well warrant greater consideration. Moreover, it is not clear how a sequential process would take into account conflicts among the principles (e.g., would there be a simple, ordinal weighting?).

The other integrative approach would be openly pluralistic, applying the principles in parallel. Such a simultaneous methodology would risk degrading into particularism, as there would be no overarching strategy. So, we might propose a heuristic such that immediate suffering is considered first (e.g., hunger from a locust plague) along with the most relevant standards (e.g., morality and capacity), followed by mitigating long-term problems arising from injustice (e.g., preventive programs for locust management) with their relevant standards (e.g., community and causal). However, as stated, even this approach would become idiosyncratic when applied to the complexity of international crises. 


\subsubsection{Connectivity}

Perhaps the most operationally viable approach to finding an optimum between a formulaic integration with a strict "decision rule" and a vague particularism with the risks of ad hoc rationalization is a kind of dynamic compromise providing structural guidance to a pluralistic integration of the standards for global justice. Miller proposes a strategy of applying the principles according to their relative strength of connection to each of the agents [? ]. For example, one agent may have a particularly strong causal responsibility, while another might have a highly developed communal obligation, and a third could have a great deal of capacity. Each then would be obligated to act in accordance with its connectivity, assuring that some agent can be held morally accountable and avoiding the problem of the agents waiting for others to act or debating who has the greatest duty. As such, international responsibility is divided among the agents such that they acknowledge connections to the afflicted people that compel action, rather than rationalizing which of the standards are inapplicable and thereby offering excuses for avoiding involvement. The result of connectivity theory is a kind of internal complexity with significant, if not formulaic, clarity - a situation that would appear to mirror real-world cases. Miller points out that this strategy does not preclude sensible ordering of standards reflecting the nature of the problem being addressed. For example, during a humanitarian crisis, capacity may be the highest priority-and whichever agent has the strongest connection to this standard would be compelled to act.

\section{Applications to Locust-Management Scenarios}

In the following scenarios of desert locust management, we construct simulations using plausible but necessarily idealized moral agents and sociopolitical relationships We considered using actual cases from the last few decades of locust management, but many of the potentially relevant details were not documented, and to generate a tractable analysis within the constraints of this paper, we would be compelled to ignore many of the nuances, organizational layers, and competing demands that were part of the record. Moreover, rather than assigning retrospective blame for past shortcomings, our goal is to illustrate the operationalization of the four principles of global justice using Miller's model of connectivity using realistic, if simplified, conditions [? ].

\subsection{Scenario 1: A Desert Locust Plague (Reactive Programs)}

\subsubsection{Scenario}

There is a serious invasion of locust swarms during a plague into country $X$ from distant sources in countries $Y$ and $Z$. All three countries are impoverished with nominal export economies. There are many subsistence farmers in $X$, a country with a weak government involved in long-term conflicts with $\mathrm{Y}$ and civil unrest within its own borders. These military actions have been conducted in political alliance with wealthy country A whose interests align with country $X$, which is a former colony, while wealthy country B has supported the militaries of countries $Y$ and $Z$. Country $X$ has provided funding to the regional locust commission $(R)$ that includes its neighbors, but tensions with countries $Y$ and $Z$ have impeded cooperation in terms of developing a strong outbreak-prevention program. All five of the countries (A, B, X, Y, and Z) are members of an international organization that was formed to provide crisis and development assistance on a global basis and whose director (I) determines the funding and logistical support allocated to the regional commission (R). An international NGO (N) is reluctantly accepted by the government of country $X$, but its work is appreciated by the local people who value the efforts to provide agricultural support and food relief to rural villages.

\subsubsection{Analysis}

There is an urgent need for assistance in country $X$ to avoid crop loss by subsistence farmers who will suffer hunger and/or loss of land in the short term and perhaps health and education detriments in the long term. 
With regard to causal responsibility, the swarms originated in countries $\mathrm{Y}$ and $\mathrm{Z}$, so their ecosystems are the proximate cause of the swarms in country $X$. However, only to the extent that the governments of countries $\mathrm{Y}$ and $\mathrm{Z}$ failed in their duties to guard against outbreaks given available resources, would they have moral (ultimate) responsibility. When considering causal responsibility in terms of contribution rather than exclusive causality, more agents bear responsibilities. The political meddling of countries A and B constitute important, if less-immediate, causes of the situation by having impeded the development of preventive approaches in the region through organization $\mathrm{R}$ with support approved by director I. In historical terms, country $X$ was a colony of country A, and this legacy accounts for a continuing lack of internal political capacity. Organization $\mathrm{N}$ has done nothing to cause the locust plague.

As for moral responsibility, the government of country $X$ has a duty to provide for its citizens. The other countries ( $\mathrm{A}, \mathrm{B}, \mathrm{Y}$, and $\mathrm{Z}$ ) have a common, humanitarian obligation to the suffering of those in country $X$. Organization $R$ has no special, moral obligation, but the director (I) has the individual duty to fulfill the charter of the organization to aid nations in peril. Organization $\mathrm{N}$ has raised its operating funds through an explicit commitment to relieving hunger.

In terms of capacity, countries $A$ and $B$ have the resources needed to mitigate the immanent suffering, while countries $X, Y$, and Z are without the financial or logistical means to fully address a locust plague. The resources from countries $A$ and $B$ could be provided bilaterally to country $X$, but director I oversees an organization constructed to receive and distribute funds to needy people, including through commission R. Organization $\mathrm{N}$ is overwhelmed by the demand for food in locust-afflicted villages.

Country $X$ is in a geopolitical community relationship with its neighbors (mere physical proximity would not constitute a community, although bordering countries typically establish international agreements). All three countries belong to the same regional locust commission (R), although this association is undermined by political hostilities. The colonial history and political bonds form a strong communal relationship between countries $\mathrm{X}$ and A. All of the countries belong to the international global community for which director I has responsibility. The director's obligations are diluted by virtue of its expansive membership. Organization $\mathrm{N}$ is begrudgingly present in the eyes of country $\mathrm{X}^{\prime}$ 's government, although its work is valued locally.

In summary, given the urgency of the situation, the moral principles might be ordered such that capacity $>$ community $>$ moral $=$ causal. Then, considering the evident strength of connections among the moral agents, the result would be one in which the responsibility for relieving the human suffering falls very strongly on country A and somewhat less on both country B and the director (I) of the international organization. Still less and relatively equal moral responsibility would accrue to countries $\mathrm{X}, \mathrm{Y}$, and Z, as well as organizations $\mathrm{R}$ and $\mathrm{N}$.

\subsection{Scenario 2: Desert Locust Recession (Preventive Programs)}

\subsubsection{Scenario}

During a recession period, countries $\mathrm{U}, \mathrm{V}$, and $\mathrm{W}$ comprise a regional commission (organization R) charged with developing outbreak-prevention programs with the support of an international organization (I). While all three countries are impoverished, $\mathrm{U}$ and $\mathrm{V}$ have functional governments, while $W$ is wracked with corruption by an authoritarian government. Countries $\mathrm{U}$ and $\mathrm{V}$ share a colonial history with country $\mathrm{C}$, a wealthy nation. Country $\mathrm{W}$ has an abundance of oil, but most of the profits flow to the world's largest energy company (E, with stockholder, e) headquartered and taxed in country $\mathrm{D}$, a wealthy nation. Historically, country $\mathrm{U}$ has few locust breeding sites; country $\mathrm{V}$ has many such habitats, but landmines (provided by country $C$ during hostilities a decade earlier) make access dangerous; country $\mathrm{W}$ also has many breeding sites, but very poor roads. Models generated by organization I predict imminent shifts in rainfall patterns as a consequence of climate change attributable to a group of industrialized countries $(G$, which includes 
$\mathrm{C}$ and $\mathrm{D})$. These precipitation patterns will expand breeding habitats in country $\mathrm{U}$ and foster those in V and $\mathrm{W}$. An international nongovernmental organization $(\mathrm{N})$ pursues agricultural-development projects in the region, but lacks expertise in locust management.

\subsubsection{Analysis}

A viable preventive program in the region $(R)$ requires the cooperation of countries $U$, $\mathrm{V}$, and $\mathrm{W}$. However, these agents cannot sustain such a program in light of their depleted economies and competing demands for healthcare, clean water, rural education, etc.

In terms of causal responsibility, a failure of prevention could be attributed to the relevant countries $(\mathrm{U}, \mathrm{V}$, and $\mathrm{W})$ and the regional organization $(\mathrm{R})$. However, the poverty of these agents can be traced to the colonialism of country $C$ (along with the landmines making access dangerous) and the exploitation of natural resources by company $\mathrm{E}$, which in turn benefits both its stockholder e and country D. The international organization (I) is limited by the funds provided by member nations. The intensification and expansion of locust breeding areas is assignable to those countries, G, responsible for emitting the greatest share of greenhouse gases.

With regard to moral responsibility, the prevention of a humanitarian disaster by a locust plague is arguably most heavily assigned to the international organization (I), given their mandate. In light of the benefits that have accrued to wealthy nations $C$ and $D$ through colonialism and continuing extraction of resources, these agents bear substantial responsibility. A similar case could be made for company E, although the direct linkage to locust-afflicted nations is somewhat weaker, and the connectivity of its stockholder (e) is much less but nonzero. The governments of $\mathrm{U}, \mathrm{V}$, and $\mathrm{W}$ also have some responsibility to their own people as well as those in the larger area, but their ethical burden is mitigated by poverty (particularly country $\mathrm{W}$, given its weak government). This reasoning also applies to the regional commission $\mathrm{R}$, although this organization has a much narrower duty than the affiliated countries and receives support from organization I. Finally, the NGO has no relevant expertise in locust management and no obligations to do that which is outside of its ability ("ought implies can").

Turning to capacity, regional organization $(R)$ and the wealthy countries $(C, D$, and the collective, G) bear the greatest burden. International organization I has a multiplicity of responsibilities, only one of which is prevention of locust plagues. The impoverished countries $(\mathrm{U}, \mathrm{V}$, and $\mathrm{W})$ have broad obligations and limited resources, as does the nongovernmental organization $\mathrm{N}$, while country $\mathrm{W}$ further lacks the political ability to contribute. The energy company $(\mathrm{E})$ has assets needed for a preventive program and a duty to provide these while meeting fiduciary obligations to its shareholders, including e, whose capacity is vanishingly small.

And finally, considering community, countries $\mathrm{U}, \mathrm{V}$, and $\mathrm{W}$ form an association geographically and through their collective support of organization $R$, which represents the locust-management community. There is a strong communal component of country $C$ with countries $\mathrm{U}$ and $\mathrm{V}$ by virtue of historical relations. Country W's government makes for a weaker communal ability, although it has an economic relationship with company E, while stockholder e participates in the corporate community. Both $\mathrm{E}$ and e therefore have an economic connection to country D. The nongovernmental organization $(\mathrm{N})$ has a strong relationship with countries $U$ and $V$, but lesser so with country $W$. Both the international organization (I) and the industrialized countries $(\mathrm{G})$ are weak elements of a community concerned with locust outbreak prevention by virtue of diverse global connections.

In summary, given the chronic, rather than acute, nature of this case, the moral principles might be ordered such that causal $=$ moral $>$ community $>$ capacity. Then, taking into account the evident strength of connectivities among the moral agents, the result would be that the greatest obligations to prevent the harm resulting from a locust plague accrue at the country level, including the wealthy $(C$ and $D)$ and impoverished ( $U$ and $\mathrm{V})$ nations. The responsibilities of the former arise in consideration of their moral duties and the latter in consideration of their causal efficacies. Of the organizations, only the 
regional commission $(\mathrm{R})$ has a high obligation, while the larger collectives ( $\mathrm{G}$ and $\mathrm{I}$ ) and the company $(\mathrm{E})$ have moderate obligations, largely due to weaker communal and causal considerations (even less for stockholder e). Likewise, country W has moderate obligations in consideration of its weak government, which undermines capacity and community. The nongovernmental organization $(\mathrm{N})$ has high moral and communal factors, but no causal responsibility or capacity, so its overall obligation is low.

\subsection{Summary}

In both scenarios (preventive and reactive), moral responsibility primarily falls to wealthy countries. However, in the preventive scenario, the allocations are more evenly distributed among countries, and the international and regional organizations bear a greater burden than in the reactive scenario. In the reactive case, the wealthy countries clearly have the greatest responsibility, which reflects the weight put on capacity during a crisis (of course, funds may pass through the international organization).

The allocation of responsibilities for global justice in these cases does not diverge markedly from what we would take to be common, moral intuitions in which causal responsibility and capacity would seem to be important considerations and wealthy countries are thought to bear the greatest burden. Rather, the advantage of adapting and applying Miller's fourfold principles along with network theory is that we have an explicit set of reasons for our ethical inclinations rather than merely doing what "seems right" without being able to explain or defend our decisions to those who fail to share our intuitions [? ]. In short, it is desirable to do the right thing, but it is far more intellectually and morally valuable to do the right thing for the right reasons.

That said, we do not possess anything approaching certainty through some sort of moral mathematics. This analysis does not yield artificially precise quantitative results that might be generated by converting the various factors into numerical values for a spreadsheet. As much as such exactitude would seem desirable, it would substitute easy answers for the hard work of democratic deliberation. So, the framework provides a means by which individuals and communities can think through the nature of their responsibilities in the course of negotiating a just approach to developing both preventive programs of locust management and reactive responses during upsurges that may become plagues.

Perhaps even more importantly, with a conceptual formalization, we now have a method for critically analyzing novel cases of locust management that are likely to emerge given rapidly changing political, economic, and environmental conditions. Unfamiliar conditions may reduce the relevancy of our experiences and lead to conflicting moral intuitions. As new situations arise, having a theoretical framework for identifying moral agents and distributing responsibilities to achieve global justice will be important.

\section{Conclusions}

Our purpose in this paper was to address the rising awareness in the field of locust management that the limiting factor in making substantive progress has become a serious consideration, as well as integration of the social sciences and humanities with the natural sciences [? ? ? ]. Oftentimes, we know what strategy and methods to implement from entomological and ecological perspectives to improve the efficacy of management, and so the obstacles are not more or better data about the insects, although greater knowledge is surely an asset, and we would not discourage continued research on locust biology with important implications for sound pest management (e.g., [? ]). Rather, the impediments are economic, political, and cultural understanding. As such, we sought to sketch an approach to making socially and ethically sound decisions about desert locust management through the framework of global justice, informed by conventional moral theories. Two findings emerged from our analysis, perhaps neither of which is terribly surprising to those in the field.

First, there is a tremendous diversity of moral agents, including individuals, scientific organizations, nongovernmental organizations, corporations, nations, government 
agencies, regional commissions, and international bodies. If anything, our analysis likely expanded the inventory of collective, moral agents while providing a sound rationale for inclusion.

Second, justly allocating responsibilities among the agents during a preventive or reactive program of locust management is a complex task. However, there are intellectually compelling principles to provide at least a working model for how these duties ought to be distributed. While natural scientists might be understandably frustrated by the imprecision of our framework, we would point out Aristotle's admonition:

For it belongs to an educated person to seek out precision in each genus to the extent that the nature of the matter allows: to accept persuasive speech from a skilled mathematician appears comparable to demanding demonstrations from a skilled rhetorician. [? ] (pp. 3-4)

While a formula for assigning responsibility is not a sensible endpoint, having the criteria for moral agency, an explicit set of principles, and a plausible, if inexact, theory for justly distributing the burdens of locust management hopefully constitutes a valuable starting point for further research and discourse. Our foray into the nexus of locust management, social science, and humanities represents a step in working toward a philosophically coherent, scientifically sound, conceptually defensible, and operationally viable method.

While our discussion of justice has an anthropocentric focus, it should be noted that many theorists of global justice have argued for expanding the boundaries of justice beyond species membership in addition to political membership. Singer, for example, argues that because all sentient creatures experience pleasure and pain, they are also deserving of moral consideration [? ]. Nussbaum also extends her capabilities approach to ground interspecies justice, based on the idea that nonhuman animals are capable of living dignified and flourishing lives, with corresponding needs to promote such flourishing [? ]. Schlosberg focuses this approach to the level of the ecosystem, rather than the individual or species, noting that harm to nonhuman animals, in recognition that individual creatures are harmed by habitat disruption and destruction and that ecosystem integrity and functioning contribute to human and nonhuman flourishing [? ].

Although a detailed engagement with questions of interspecies justice is beyond the scope of this paper, these arguments raise important questions in the context of locust swarms that demand further interdisciplinary research. Insofar as locust swarms and their management disrupt the integrity and functioning of ecosystems, they may generate obligations of justice on behalf of those ecosystems, especially when such disruptions are caused by anthropogenic climate change. Furthermore, management strategies should be sensitive to ecosystem functioning and integrity, and the long-term ecological consequences must be considered when evaluating the justice of both preventive and reactive strategies. Finally, the moral framework we have proposed does not solve the political problem of actually getting agents (especially powerful states) to bear their responsibilities with regard to locust management. That is a topic for another line of research that must incorporate scholarship in political theory, including Schiff's work on how different ways of narrating injustices can affect how agents acknowledge and act upon their responsibilities [? ], and Ackerly's human-rights model of responsibility, which identifies principles-in-practice for agents to leverage their existing social roles and relationships to discharge their responsibilities for combatting injustice [? ]. Our goal is that, having opened up space for dialogue between natural scientific research on desert locust management and political and moral philosophies of global justice, future scholarship can engage the questions our analysis generates.

Author Contributions: Conceptualization, J.A.L. and M.C.S.; methodology, J.A.L. and M.C.S.; formal analysis, J.A.L. and M.C.S.; writing—original draft preparation, J.A.L.; writing—review and editing, M.C.S.; investigation, J.A.L. and M.C.S. Both authors have read and agreed to the published version of the manuscript.

Funding: This research received no external funding. 
Acknowledgments: The authors are grateful to the editors and reviewers for helpful and constructive feedback.

Conflicts of Interest: The authors declare no conflict of interest.

\section{References}

1. Uvarov, B. Grasshoppers and Locusts: A Handbook of General Acridology; Cambridge University Press: London, UK, 1966 ; Volume 1.

2. Uvarov, B. Grasshoppers and Locusts: A Handbook of General Acridology; Centre for Overseas Pest Research: London, UK, 1977; Volume 2.

3. Pener, M.P. Endocrine aspects of phase polymorphism in locusts. In Endocrinology of Insects; Downer, R.G.H., Laufer, H., Eds.; Alan R. Liss: New York, NY, USA, 1983; pp. 379-394.

4. Cullen, D.A.; Cease, A.V.; Latchininsky, A.V.; Ayali, A.; Berry, K.; Buhl, J.; Keyser, R.D.; Foquet, B.; Hadrich, J.C.; Matheson, T.; et al. From molecules to management: Mechanisms and consequences of locust phase polyphenism. Adv. Insect Phys. 2017, 53, 165-185.

5. Symmons, P. A critique of "Preventive control and desert locust plagues". Crop Prot. 2009, 28, 905-907. [CrossRef]

6. Medina, H.; Cease, A.; Trumper, E. The resurgence of the South American locust (Schistocerca cancellata). Metaleptea 2017, 37, $17-21$.

7. Zhang, L.; Lecoq, M.; Latchininsky, A.; Hunter, D. Locust and grasshopper management. Annu. Rev. Entomol. 2019, 64, 15-34 [CrossRef]

8. Symmons, P.M.; Cressman, K.K. Desert Locust Guidelines; Food and Agricultural Organization of the United Nations: Rome, Italy, 2001.

9. Lecoq, M. Le criquet pélerin: Enseignements de la dernière invasion et perspectives offertes par la biomodélisation. In La Lutte Anti-Acridienne; Essaid, A., Ed.; Faculté des Sciences, CIRUISEF, AUPELF-UREF: Paris, France, 1991; pp. 71-98.

10. Doré, A.; Barbier, M. Maintenir la vigilance. Rev. Anthropol. Connaiss. 2015, 9, 189-212. [CrossRef]

11. Gay, P.-E.; Lecoq, M.; Piou, C. The limitations of locust preventive management faced with spatial uncertainty: Exploration with a multi-agent model. Pest Manag. Sci. 2019, 76, 1094-1102. [CrossRef] [PubMed]

12. De Vreyer, P.; Guilbert, N.; Mesple-Sompsa, S. Impact of natural disasters on education outcomes: Evidence from the 1987-89 locust plague in Mali. J. Afr. Econ. 2014, 24, 57-100. [CrossRef]

13. Manthey, S. Curse of the Good Rains: The Long-Run Impacts of Locust Infestations, Evidence from the 1986-1989 Locust Plague in the Sahel. Master's Thesis, Lund University, Lund, Sweden, 2020.

14. Showler, A.T. The desert locust in Africa and Western Asia: Complexities of war, politics, perilous terrain, and development. In Radcliffe's IPM World Textbook; Radcliffe, E.B., Hutchison, W.D., Cancelado, R.E., Eds.; University of Minnesota: St. Paul, MN, USA, 2019.

15. Lecoq, M. Recent progress in desert and migratory locust management in Africa: Are preventative actions possible? J. Orthop. Res. 2001, 10, 277-291. [CrossRef]

16. Magor, J.I.; Lecoq, M.; Hunter, D.M. Preventive control and desert locust plagues. Crop Prot. 2008, 27, 1527-1533. [CrossRef]

17. van Huis, A.; Cressman, K.; Magor, J.I. Preventing desert locust plagues: Optimizing management interventions. Entomol. Exp. Appl. 2007, 122, 191-214. [CrossRef]

18. Abou-Ali, H.; Belhaj, M. Cost Benefit Analysis of Desert Locust Control: A Multicountry Perspective. Economic Research Forum Working Papers. 2008. Available online: https:/ / econpapers.repec.org/paper/ergwpaper/801.htm (accessed on 11 January 2021).

19. Millist, N.; Abdalla, A. Benefit-Cost Analysis of Australia Plague Locust Control Operations for 2010-2011; Australian Bureau of Agricultural and Resource Economics and Sciences: Canberra, Australia, 2011.

20. Latchininsky, A.V. Locusts and remote sensing: A review. J. Appl. Rem. Sens. 2013, 7. [CrossRef]

21. Lecoq, M. Desert locust management: From ecology to anthropology. J. Orthop. Res. 2005, 14, 179-186. [CrossRef]

22. Toleubayev, K.; Jansen, K.; van Huis, A. Locust control in transition: The loss and reinvention of collective action in post-Soviet Kazakhstan. Ecol. Soc. 2007, 12, 38. [CrossRef]

23. De Vreyer, P.; Guilbert, N.; Mesplé-Somps, S. The 1987-1989 Locust Plague in Mali: Evidences of the Heterogeneous Impact of Income Shocks on Education Outcomes; Working Papers No DT/2012/05; Örebro University School of Business: Örebro, Sweden, 2012.

24. Péloquin, C. Unruly Nature and Technological Authority: Governing Locust Swarms in the Sahel. Ph.D. Thesis, University of Arizona, Tucson, AZ, USA, 2014.

25. Cease, A.J.; Elser, J.J.; Fenichel, E.P.; Hadrich, J.C. Living with locusts: Connecting soil nitrogen, locust outbreaks, livelihoods, and livestock markets. BioScience 2015, 65, 551-558. [CrossRef]

26. Deshormes, A. Institutional Study to Enhance the Roles and Responsibilities of the Desert Locust Control Commission Established under Article XIV; Food \& Agriculture Organization of the United Nations: Rome, Italy, 2011.

27. Tom, K. The UN Should Learn That Ideology Won't Stop a Plague of Locusts. Real Clear World Website. Available online: https:/ / www.realclearworld.com/2020/08/06/un_ideology_wont_stop_a_plague_of_locusts_501135.html (accessed on 11 January 2021).

28. Metlerkamp, L.U.S. Agribusiness Takes Aim at Global Food Policy Reform. Available online: https://foodtank.com/news/2020 /05/u-s-agribusiness-takes-aim-at-global-food-policy-reform/ (accessed on 11 January 2021).

29. Lecoq, M. Some considerations of the current desert locust situation in East Africa. Metaleptea 2020, 40, $25-26$. 
30. Gay, P.-E.; Lecoq, M.; Piou, C. Improving preventive locust management: Insights from a multi-agent model. Pest Manag. Sci. 2018, 74, 46-58. [CrossRef] [PubMed]

31. Food \& Agriculture Organization of the United Nations. Locust watch. Desert Locust Bull. 2019, 483, 1-8.

32. Bodin, Ö. Collaborative environmental governance: Achieving collective action in social-ecological systems. Science 2017, 357, eaan1114. [CrossRef]

33. Blair, B.; Lovecraft, A.L.; Hum, R. The disaster chronotope: Spatial and temporal learning in governance of extreme events. In Governance of Risk, Hazards and Disasters; Forino, G., Bonati, S., Calandra, L.M., Eds.; Routledge: London, UK, 2018 ; pp. 43-64.

34. Shi, P.; Li, N.; Ye, Q.; Dong, W.; Han, G.; Fang, W. Research on integrated disaster risk governance in the context of global environmental change. Int. J. Disaster Risk Sci. 2010, 1, 17-23. [CrossRef]

35. Meynard, C.N.; Lecoq, M.; Chapuis, M.P.; Piou, C. On the relative role of climate change and management in the current Desert Locust outbreak in East Africa. Glob. Chang. Biol. 2020, 26, 3753-3755. [CrossRef]

36. Salih, A.A.M.; Baraibar, M.; Mwangi, K.K.; Artan, G. Climate change and locust outbreak in East Africa. Nat. Clim. Chang. 2020, 10, 584-585. [CrossRef]

37. Thomas, N.; Nigam, S. Twentieth-century climate change over Africa: Seasonal hydroclimate trends and Sahara desert expansion. J. Clim. 2018, 31, 3349-3370. [CrossRef]

38. Food \& Agriculture Organization of the United Nations. Desert Locust. Available online: http://www.fao.org/locusts/en/ (accessed on 11 January 2021).

39. Latchininsky, A.; Sword, G.; Sergeev, M.; Cigliano, M.M.; Lecoq, M. Locusts and grasshoppers: Behavior, ecology, and biogeography. Psyche 2011, 2011, 578327. [CrossRef]

40. Food \& Agriculture Organization of the United Nations. Locust Watch. Available online: http://www.fao.org/ag/locusts/en/ info/2094/2548/index.html (accessed on 11 January 2021).

41. Belayneh, Y.T. Acridid pest management in the developing world: A challenge to the rural population, a dilemma to the international community. J. Orthoptera Res. 2005, 14, 187-195. [CrossRef]

42. Brader, L.; Djibo, H.; Faye, F.G.; Ghaout, S.; Lazar, M.; Luzietoso, P.N.; Ould Babah, M.A. Towards a More Effective Response to Desert Locusts and Their Impacts on Food Security, Livelihoods and Poverty: Multilateral Evaluation of the 2003-2005 Desert Locust Campaign; Food \& Agriculture Organization of the United Nations: Rome, Italy, 2006.

43. Lockwood, J.A.; Showler, A.T.; Latchininsky, A.V. Can we make locust and grasshopper management sustainable? J. Orthop. Res. 2001, 10, 315-329. [CrossRef]

44. Driver, J. The History of Utilitarianism. In The Stanford Encyclopedia of Philosophy; Zalta, E.N., Ed.; 2014. Available online: https:/ / plato.stanford.edu/archives/win2014/entries/utilitarianism-history/ (accessed on 11 January 2021).

45. Alexander, L.; Moore, M. Deontological Ethics. In The Stanford Encyclopedia of Philosophy; Zalta, E.N., Ed.; 2016. Available online: https:/ / plato.stanford.edu/archives/win2016/entries/ethics-deontological/ (accessed on 11 January 2021).

46. Hursthouse, R.; Pettigrove, G. Virtue Ethics. In The Stanford Encyclopedia of Philosophy; Zalta, E.N., Ed.; 2018. Available online: https:/ / plato.stanford.edu/archives/win2018/entries/ethics-virtue/ (accessed on 11 January 2021).

47. Singer, P. Famine, affluence, and morality. Philos. Public Aff. 1972, 1, 229-243.

48. O'Neill, O. Kantian approaches to some famine problems. In Matters of Life and Death; Reagan, T., Ed.; McGraw-Hill: New York, NY, USA, 1993; pp. 258-270.

49. MacIntyre, A. After Virtue: A Study in Moral Theory, 3rd ed.; University of Notre Dame Press: Notre Dame, IN, USA, 2007.

50. Van Hooft, S. Cosmopolitanism as virtue. J. Glob. Ethics 2007, 3, 303-315. [CrossRef]

51. Hayek, F.A. The Collected Works of F. A. Hayek Volume XVII: The Constitution of Liberty; Hamowy, R., Ed.; University of Chicago Press: Chicago, IL, USA, 2011.

52. Sandel, M.J. Justice: What's the Right Thing to Do? Farrar, Straus and Giroux: New York, NY, USA, 2009.

53. Rawls, J. A Theory of Justice; Harvard University Press: Cambridge, MA, USA, 1971.

54. Young, I.M. Justice and the Politics of Difference; Princeton University Press: Princeton, NJ, USA, 1990.

55. Goodhart, M. Injustice: Political Theory for the Real World; Oxford University Press: New York, NY, USA, 2018.

56. Lockwood, J.A.; Kemp, W.P.; Onsager, J.A. Long-term, large-scale effects of insecticidal control on rangeland grasshopper populations. J. Econ. Entomol. 1988, 81, 1258-1264. [CrossRef]

57. Shue, H. Climate Justice: Vulnerability and Protection; Oxford University Press: New York, NY, USA, 2014.

58. Acemoglu, D.; Johnson, S.; Robinson, J.A. The colonial origins of comparative development: An empirical investigation. Am. Econ. Rev. 2001, 91, 1369-1401. [CrossRef]

59. Shklar, J. The Faces of Injustice; Yale University Press: New Haven, CT, USA, 1990.

60. Erskine, T. Assigning responsibilities to institutional moral agents: The case of states and quasi-states. Ethics Int. Aff. 2001, 15, 67-85. [CrossRef]

61. Rawls, J. The Law of Peoples: With, the Idea of Public Reason Revisited; Harvard University Press: Cambridge, MA, USA, 1999.

62. Beitz, C.R. Justice and international relations. Philos. Public Aff. 1975, 4, 360-389.

63. Shue, H. Basic Rights: Subsistence, Affluence, and U.S. Foreign Policy; Princeton University Press: Princeton, NJ, USA, 1980.

64. Nussbaum, M. Capabilities and social justice. Int. Stud. Rev. 2002, 4, 123-135. [CrossRef]

65. Nagel, T. The problem of global justice. Philos. Public Aff. 2005, 33, 113-147. [CrossRef]

66. Miller, D. Cosmopolitanism: A critique. Crit. Rev. Int. Soc. Political Philos. 2002, 5, 80-85. [CrossRef] 
67. Forst, R. Towards a critical theory of transnational justice. Metaphilosophy 2001, 32, 160-179. [CrossRef]

68. Kant, I. The Metaphysics of Morals; Gregor, M., Translator; Cambridge University Press: Cambridge, UK, 1996.

69. Feinberg, J. Collective responsibility. J. Philos. 1968, 65, 674-688. [CrossRef]

70. O'Neill, O. Agents of justice. Metaphilos 2001, 32, 180-195. [CrossRef]

71. Young, I.M. Responsibility for Justice; Oxford University Press: New York, NY, USA, 2011.

72. French, P. Collective and Corporate Responsibility; Columbia University Press: New York, NY, USA, 1984.

73. Global Locust Initiative, Arizona State University Global Sustainability. Available online: https://sustainability.asu.edu/globallocust-initiative/ (accessed on 11 January 2021).

74. Sen, A. Capability and well-being. In The Quality of Life; Nussbaum, M.C., Sen, A., Eds.; Clarendon Press: Oxford, UK, 1993; pp. 30-53.

75. Caney, S. Climate change and the duties of the advantaged. Crit. Rev. Int. Soc. Political Philos. 2010, 13, 203-228. [CrossRef]

76. Sardo, M.C. Responsibility for climate justice: Political not moral. Eur. J. Political Theory 2020. [CrossRef]

77. Young, I.M. Responsibility and global justice: A social connection model. Soc. Philos. Policy 2006, 23, 102-130. [CrossRef]

78. van de Walle, N. Economic reform in a democratizing Africa. Comp. Political 1999, 32, 21-41. [CrossRef]

79. Miller, D. National Responsibility and Global Justice. Crit. Rev. Int. Soc. Political Philos. 2008, 11, 383-399. [CrossRef]

80. Shue, H. Global environment and international inequality. Int. Aff. 1999, 75, 531-545. [CrossRef]

81. Caney, S. Cosmopolitan justice, responsibility, and global climate change. Leiden J. Int. Law 2005, 30, 747-775. [CrossRef]

82. Vanderheiden, S. Knowledge, uncertainty, and responsibility: Responding to climate change. Public Aff. Q. 2004, 18, 141-158.

83. Sörlin, S. Environmental humanities: Why should biologists interested in the environment take the humanities seriously? BioScience 2012, 62, 788-789. [CrossRef]

84. Sword, G.A.; Lecoq, M.; Simpson, S.J. Phase polyphenism and preventative locust management. J. Insect Phys. 2010, 56, 949-957. [CrossRef]

85. Aristotle. Aristotle's Nicomachean Ethics; Bartlett, R.C.; Collins, S.D., Translators; University of Chicago Press: Chicago, IL, USA, 2012.

86. Singer, P. Animal Liberation; HarperCollins Publishers Inc.: New York, NY, USA, 2002.

87. Nussbaum, M.C. Frontiers of Justice: Disability, Nationality, Species Membership; The Belknap Press of Harvard University Press: Cambridge, MA, USA, 2007.

88. Schlosberg, D. Defining Environmental Justice: Theories, Movements, and Nature; Oxford University Press: Oxford, UK, 2007.

89. Schiff, J.L. Burdens of Political Responsibility: Narrative and the Cultivation of Responsiveness; Cambridge University Press: Cambridge, UK, 2014.

90. Ackerly, B.A. Just Responsibility: A Human Rights Theory of Global Justice; Oxford University Press: New York, NY, USA, 2018.

\section{Short Biography of Authors}

Jeffrey Alan Lockwood Professor of Natural Sciences and Humanities, Department of Philosophy and Religious Studies, University of Wyoming (2003-present). B.S. in Biology, New Mexico Tech, 1982; Ph.D. in Entomology, Louisiana State University, 1985. Professor of Entomology, University of Wyoming (1986-2003); Visiting Fellow, CSIRO Division of Entomology, Canberra, Australia (1993-1994); Research Fellow, Organization for Economic Cooperation and Development, AgResearch, Mosgiel, New Zealand. Research interests include ecology and management of rangeland grasshoppers, environmental ethics, and philosophy of science. Member of Entomological Society of America, Orthopterists Society, Independent Book Publishers Association, American Society of Composers, Authors and Publishers. Awards include: Western Region Extension Directors Association Award of Excellence, Finalist for Best Contemporary Nonfiction from Western Writers of America, Silver medal for the Benjamin Franklin Award from the Independent Book Publishers Association, John Burroughs Award, Albert Schweitzer Award, Pushcart Prize, and University of Wyoming's: Extraordinary Merit in Research Award and Excellence in Internationalization Award.

Michael Christopher Sardo Non-Tenure Track Assistant Professor, Department of Politics, Occidental College (2019-present). B.A. in Government and Philosophy, The College of William and Mary in Virginia, 2011; M.A. and Ph.D. in Political Science, Northwestern University, 2017. Research interests include political responsibility, global justice, climate change, the anthropocene, and the history of political thought. 